\title{
A Review Paper on Seismic Pareformance of High-Rise Building using Bracing, Diagrid and Outrigger System
}

\author{
Mustafa Hussini \\ Department of civil engineering \\ Chandigarh University \\ Mohali, Punjab, India
}

\author{
Sandeep Nasier \\ Department of civil engineering \\ Chandigarh University \\ Mohali, Punjab, India
}

\begin{abstract}
As the population of world is increasing day by day the need for high-rise building grows equally to it, but as the height of buildings increases the challenge to tackle lateral load in building will difficult and challengeable for engineers and designers. To stabilize the building against lateral load there are number of structural system to resist lateral in building without any addition to building's overall plan area or tonnage of the building. One of the most commonly used structural system that is used for stabilization of high-rise building against lateral load is bracing system, it can be used in both condition of the building it can be used as retrofitting or as system in design of the building. It transfer lateral load by means of tension and compression action. Another system that is a new concept that changes vertical columns orientation to diagonal that changes all types of load to axial load to transfer them safely to the foundation. One of the structural systems that can be used as lateral load resisting system that adds to the buildings lateral stiffness and strength is outrigger system that is very effective system in case of resisting lateral load. In current paper the above three mentioned system will be reviewed.
\end{abstract}

Keywords-Lateral load resisting system, high-rise building, outrigger system, bracing system, diagrid system

\section{INTRODUCTION}

When height of the building increases it is more vulnerable to the lateral load so the designing need to be done carefully and structural system need to be selected according to the building's requirements so a building will be designed as per standards, which transfer lateral and vertical loads to the foundation safely. To resist lateral loads there are number of lateral load resisting system, bracing system is one of it that can be used as retrofitting for strengthening of the building or as lateral load resisting system. Diagrid is another structural system is newly developed mechanism for resisting lateral loads. Outrigger structural system can be used to increase the building lateral strength and stiffness.

\section{BRACING SYSTEM}

It is a structural system that commonly used as lateral load resisting system to resist lateral loads such as wind and earthquake. Bracing system transfer lateral loads by means of tension and compression action, it means that when lateral load act on the building one will undergo tension and another will undergo compression. So the material commonly used in bracing is steel that has good strength in tension as well as compression. The beams and columns in a frame will carry vertical load and bracing will carry lateral loads. Positioning of bracing can be problematic as it interfere with position of opening and design of façade. Or it can be displayed as internal or external design feature.

\section{DIAGRID SYSTEM}

Diagrid structural system is a newly developed structural system that attracted the interest of both architectures and designers due its good aesthetic view and resistance against lateral loads. The diagonal members of diagrid system gives a very attractive view to the building from outside the building and can resist both gravity as well as lateral loads at the same time. It is possible because of its unique geometry and combination of its member. Diagonal members at the periphery of the building gives a lot of space for façade designing purpose and openings, this is one of the unique advantages that diagrid system has over the other structural systems.

\section{OUTRIGGER SYSTEM}

For the buildings that has height of more than 40 stories it braced frame system become inefficient because excessive bracing will be required to provide adequate lateral stiffness, by providing horizontal belt truss that tie frame to the core of the building that will improve structural efficiency of the building by $30 \%$. The trusses need to be fixed rigidly to the core and simply connected to the outer columns. Belt trusses act as lever arms that transfer axial stresses of core to the outer columns whenever the core undergoes bending. To resist lateral displacement of the core, columns act as struts. The core develop horizontal shear and belt truss transfer vertical shear to the outrigger frame.

\section{LITERATURE REVIEW}

Sagar L. Belgaonkar, Akshata A. Mulgund and Prabha Bharat Patil (2019): a research has been conducted on “ seismic analysis of vertically irregular RC framed structure using X-bracing and bundle tube in various zones using Staad pro Software" in this paper the structure is analyzed with Xbracing and bundle tube on a G+20 storey structure. And they found that time period of $\mathrm{Tn}=1.35 \mathrm{sec}$, it is increased by $38.95 \%$ as compared to conventional building. And in zone III it was increased by $9 \%$ compared to zone IV and Zone V. with time period $\mathrm{Tn}=1.17 \mathrm{sec}$, it was increased by by $38.94 \%$ as compared to conventional building. And also found that it was less increased in zone III by $8.98 \%$ compared to zone IV and V. 
Karnati Vijetha and B. Panduranga Rao (2019): a research has been conducted on " comparative study of shear walls and bracing for multistoried structure under seismic loading" a G+15 multisotrey building is analyzed by using share wall and braced frame at outer most of the structure and comparison with multistoried structure using ETABS. And it was fond that the time period of designed structures were highly reduced after placing of bracing and share walls with comparison to conventional building.

Abdul Halim Etemad and Aditya Kumar Tiwary (2019): conducted a research on "comparison of tubular, outrigger and bracing system for stabilization of high-rise building" in this paper comparison of tubular, outrigger and bracing system has been studied on a 42 storey RC building using standard package of ETABS 2016, and found that $46.7 \%$ increase in lateral deflection in $\mathrm{X}$-direction and $55.23 \%$ in $\mathrm{Y}$-direction as compare to outrigger system and also found that base shear reduction of $43.17 \%$ in outrigger system as compare to tube system which has the maximum base shear.

Trupti A. Kinjawadekar and Amit C. Kinjawadekar (2018): conducted a study on "comparative study of seismic characteristic of diagrid structural system in high-rise construction" the study aims to explore the applicability of diagrid structures in high-rise structures, over the traditional construction system numerical models and seismic characteristics of diagrid members have been studied using software SAP-2016 and concluded that storey drift and storey shear result are much lesser in the region of diagrid angle $45^{\circ}$ to $64^{\circ}$ to structures with 36 storey, the storey drift and sotrey shear result are lesser region of diagrid angle of $64^{\circ}$.

Akshat and Gurpreet singh (2018): conducted a research on " dynamic analysis of diagrid structural system in high-rise steel building" the study was made on the basis of lateral load due to earthquake. In this paper a 60 storey tall building with total height of $216 \mathrm{~m}$ was analyzed. The plan dimension of the building is $48 \times 48 \mathrm{~m}$. the building was analyzed for lateral load due to earthquake in seismic zone IV. Various patterns of diagrid were used in the dynamic analysis of the structure and found out that about $20 \%$ less reduction of steel in diagrid structure as compared to conventional structure. Also found that the efficient results for geometrical diagrid patterns are in between the angles of $67.38^{\circ}$ and $71.56^{\circ}$.

Pankaj Sharma and Gurpreet singh (2018): a research has been conducted on dynamic analysis of outrigger system in high-rise building against lateral loads" the study has been made on dynamic analysis outrigger system for a 60 storey building having an overall height of $180 \mathrm{~m}$. and has found that for earthquake load inverted V combined with 4 outriggers is the most effective as maximum storey displacement decreases by $14.43 \mathrm{~mm}(3.64 \%)$ without belt truss and $21.77 \mathrm{~mm}(5.5 \%)$ with belt truss. In case of shear wall outriggers the displacement decreases by $87.34 \mathrm{~mm}(22.06 \%)$ without shear band and $98 \mathrm{~mm}(24.75 \%)$ with shear band. For wind load inverted $\mathrm{V}$ combined with 4 outriggers is most effective a maximum storey displacement decreases by $11.04 \mathrm{~mm}$ $(3.71 \%)$ without belt truss and $16.72 \mathrm{~mm}(5.61 \%)$ with belt truss. In case of shear wall outriggers the displacement decreased by $68.29 \mathrm{~mm}(22.92 \%)$ without shear band and $79.22 \mathrm{~mm}(2.59 \%)$ with shear band.

Nauman Mohammed and Islam Nasrul (2013); in this paper the author have done a research on behavior of multistorey RCC structure with different types of bracing on $\mathrm{G}+14$ storey building, and they found that cross bracing have reduced the lateral deflection, bending moment and base shear up to an acceptable range.

Roslida Abd Samat, Muhammed Fikri Khairudin and Muhammed Haziq Din (2019); they have done a research on comparative structural performance of diagrid and bracing system in mitigation of lateral displacement on buildings with 40,60 and 80 storey with a storey height of $4 \mathrm{~m}$, and they found that 80 degree diagrid the most effective system to reduce lateral displacement for buildings that have less than 71 stories while X-bracing has done better for building with height more than 71 sotries. And they also found that torsional natural frequency has increased by $20 \%$ when 60 degree diagrid was used for an 80 storey building.

Viren P. Ganatra, Prof. Rashida A. Jhummarwala and Dr. Kaushal B. Parikh (2017); in this paper a research have been done on behavior of outrigger system on high-rise structure by varying outrigger depth on a 50 storey building, and they come to this conclusion that for a 50 storey building by decreasing depth of outrigger to $2 / 3^{\text {rd }}, 1 / 3^{\text {rd }}$ and $1 / 2$ of the storey height the lateral displacement and lateral drift was reduced by $3-4 \%$ and $5-6 \%$ respectively in comparison with full depth. Hence lateral drift increases with reduction of outrigger height. Outrigger system is not only efficient in controlling the lateral displacement but it reduces the lateral drift significantly.

Sudheer S. and Shyam chamberlin. K (2018); they have done a research on response simulation of $\mathrm{RC}$ frame with different bracing system on a 8 storey building. And they find out that X-bracing effectively reduced the storey drift, displacement and increased the building's stiffness

\section{RESULT AND DISCUSSION}

The above literature reviews indicates that among these three lateral load resisting system that were analyzed by different researchers by using STAAD Pro and ETABS software diagrid and outrigger systems are doing better.

- The use of bracing as lateral load resisting system works good for building up to a certain level and height. That is good up to 30-35 stories.

- Diagrid system is adding to the building lateral strength and stiffness and doing better than bracing system.

- Outrigger system is a very efficient system for buildings with high-rise and super high-rise. 


\section{REFRENCES}

1. Akshat, \& Singh, G. (2018). Dynamic analysis of diagrid structural system in high rise steel buildings. International Journal of Civil Engineering and Technology, 9(8), 71-79.

2. Belgaonkar, P. S. L., Mulgund, P. A. A., \& Patil, P. B. (2019). Seismic Analysis of Vertically Irregular RC framed Structure using $X$ - Bracing and Bundle Tube in Various Zones using STAAD Pro Software. 8(07), 323-327.

3. Etemad, A. H., \& Kumar Tiwary, A. (2019). Article ID: IJCIET 10_03 196 Cite this Article: Abdul Halim Etemad and Aditya Kumar Tiwary, Comparison of Tubular, Outrigger and Bracing System for Stabilization of High-Rise Buildings. International Journal of Civil Engineering and Technology (IJCIET), 10(03), 1968-1977.

4. Ganatra, V. P., Jhummarwala, P. R. A., \& Parikh, K. B. (2017) Study on Behaviour of Outrigger System on High. 5(Ix), 2017-2022.

5. Indexed, S., Fields, G., Pradesh, A., Fields, G., \& Pradesh, A. (2018). RESPONSE SIMULATON OF RC FRAME WITH. 9(6), 9398.

6. Kinjawadekar, T. A., \& Kinjawadekar, A. C. (2018). Article ID: IJCIET_09_06_036 Cite this Article: Trupti A. Kinjawadekar and Amit C. Kinjawadekar, Comparative Study of Seismic Characteristics of Diagrid Structural Systems In High Rise Construction. International Journal of Civil Engineering and Technology (IJCIET, 9(6), 315-323.

7. Mohammed, N., \& Nazrul, I. (2013). Behaviour of Multistorey RCC Structure with Different Type of Bracing System ( A Software Approach ). 2(12), 7465-7478.

8. Samat, R. A., Khairudin, M. F., \& Din, M. H. (2019). Comparative Structural Performance of Diagrid and Bracing System in Mitigation of Lateral Displacement Comparative Structural Performance Of Diagrid and Bracing System in Mitigation of Lateral Displacement. https://doi.org/10.1088/1755$1315 / 220 / 1 / 012025$
9. Sharma, P., \& Singh, G. (2018). DYNAMIC ANALYSIS OF OUTRIGGER SYSTEMS IN HIGH RISE BUILDING AGAINST. 9(8), 61-70.

10. Vijetha, K., \& Rao, B. P. (2019). Comparative Study of Shear Walls and Bracings for A Multistoried Structure Under Seismic Loading. 8(07), 420-461.

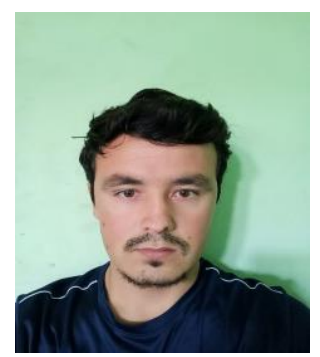

\author{
Musatafa Hussaini \\ ME.student \\ Department of Civil Engineering \\ Chandigarh University \\ Mohali, Punjab, India
}

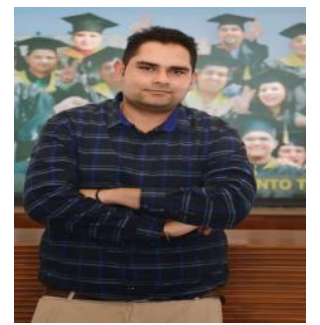

Sandeep Nasier

Assistant professor

Department of Civil Engineering

Chandigarh University

Mohali, Punjab, India 